\title{
The Effect of Calcium Hydroxide and File Sizes on the Accuracy of the Electronic Apex Locator in Simulated Immature Teeth
}

\author{
Leyla Benan Ayranci ${ }^{1}$, Ahmet Çetinkaya ${ }^{1}$, Serkan Özkan ${ }^{2}$ \\ ${ }^{1}$ Department of Endodonty, Faculty of Dentistry, Ordu University, Ordu, Turkey \\ ${ }^{2}$ Department of Orthodonty, Faculty of Dentistry, Ordu University, Ordu, Turkey
}

Received: 26 December 2019, Accepted: 28 December 2019, Published online: 31 December 2019

(C) Ordu University Institute of Health Sciences, Turkey, 2019

\begin{abstract}
Objective: The aim of this research was to appreciate the effects of different file sizes and the presence of calcium hydroxide on the correctness of the electronic apex locator (EAL) at simulated immature teeth.

Methods: In this study, 30 maxillary central teeth were used beforehand extracted due to periodontal reasons. The actual root canal length determined with K-File and measured behind $0,5 \mathrm{~mm}$ from the apex. In order to simulate an immature tooth, the apical of roots were prepared with a diameter of 1,4mm Gates-Glidden drills and K-Files. Working lengths of samples were measured using the Root ZX by 110-140 K-Files. Each measurement was repeated three times and averaged. Then all the samples were filled with calcium hydroxide medicament and working lengths were determined by the same method. Statistical analysis was performed using the Two-way ANOVA.

Results: The measurements were closer to the actual root canal length as the diameter of the file increased at the presence and absence of calcium hydroxide. However, there was a difference between the presence and absence of calcium hydroxide in the determination of root canal length.

Conclusions: In these experimental study conditions, it was concluded that the presence of calcium hydroxide in simulated immature teeth and file size affect the EAL.

Key words: Apex Locater, Root Canal, Calcium Hydroxide
\end{abstract}

Suggested Citation: Ayranci LB, Cetinkaya A, Ozkan S. The Effect of Calcium Hydroxide and File Sizes on the Accuracy of the Electronic Apex Locator in Simulated Immature Teeth. Middle Black Sea Journal of Health Science, 2019; 5(2):273-278

\section{Address for correspondence/reprints:}

Leyla Benan Ayranc1

Telephone number: +90 (506) 3590397

E-mail: dt_lbenan@hotmail.com

DOI: $10.19127 / \mathrm{mbsjohs.665667}$

Note: This study was presented in 25. Izmir Dentist Room International Scientific Congress and Exhibition as an oral presentation.

\section{Introduction}

In endodontic preparation and filling of the root canal, apical contraction is considered to be the limiting point of treatment. In epidemiological studies, the working length control is very important and histological studies have reported that optimal improvement is achieved when there is minimal contiguity between the root canal obturation material and the periapical tissue (Sjogren et al., 1990). Accurate determination of working length is a very important component of successful root canal treatment. The traditional methods such as radiography, anatomical averages of canal length, wet paper point and finger sensitivity used to determine root canal length may be insufficient at this point (Sharma and Arora, 2010). Traditionally, 
the radiographs taken after the insertion of the file in the root canal are used to determine the working length. Limitations of conventional radiographs include sensitivity technique, magnification, distortion of images, and superposition of anatomic structures. Another disadvantage of radiographs is the danger of ionizing radiation (Gordon and Chandler, 2004). Recently, electronic methods used to determine the root canal length are more widely accepted methods (Baldi et al., 2007).

Cone beam computed tomography (CBCT) is primarily used all the time in the department of oral surgery. For endodontic usage, the definite location and dimension of the pulp cavity can be visualized in 3D for an access-cavity preparation and working length may also be determined in CBCT images and combined with EAL can be useful for working length determination (Jeger et al., 2012).

The anatomical features of the extended apical foramina, development of incomplete root formation, root resorption or non-development of the root can cause difficulties on working length determination (Nguyen et al., 1996). At the same time, different sizes of files, the type of irrigation solution used are among the factors affecting the conductivity of the EAL. Many researchers recommend Ingle's method, the radiographic prediction of the working length 1-2 $\mathrm{mm}$ short of the radiographic apex determined from a preoperative radiograph or from tactile sense while some investigator advocate instrumented to the radiographic apex during treatment of immature permanent teeth with open apices (Ingle, 1994). Although radiographic method was the main method in determining the length of study in the treatment of open apexed teeth, clinical studies and case reports reported variations in the method (Pratten and McDonald, 1996). The European Society of Endodontology recommends the use of an EAL followed by verification of canal length with an undistorted radiograph during root canal treatment (Lost, 2006).

Due to its antibacterial and biological properties, calcium hydroxide is frequently used clinically (Athanassiadis et al., 2007). It is a energetic alkaline material, which has a $\mathrm{pH}$ of there about 12,5 . This agent has been attributed to various biological properties such as antimicrobial activity, tissue dissolving ability, inhibition of tooth resorption and induction of hard tissue formation and repair. Currently, calcium hydroxide used in endodontic treatment is considered one of the most effective antimicrobial agents. (Freeman and Crapo, 1982).
Clinically, the initial working length determination with EAL is mostly fixed with a small-sized file. However, whether the accuracy of EAL is affected by the use of small-sized files on open apices roots are not explained (Ebrahim et al., 2006). The null hypotheses were tested: (1) In immature root canals, the accuracy of the EAL may be affected by the file size because a small diameter file is likely to leave a space in the root canal, whereas a larger diameter root canal provides a closer fit with the dentin. (2) Due to the inorganic structure of calcium hydroxide, more accurate results can be obtained as it provides more contact between file and the root dentin wall. The aims of this in vitro study were to evaluate the accuracy of Root ZX (Morita, Tokyo, Japan) apex locator measurements with 110 to $140 \mathrm{~mm}$ diameter files in enlarged simulated immature root canals and to analyze effects of the calcium hydroxide.

\section{Methods}

Thirty extracted human maxillary anterior teeth with a single root canal were selected. In this study, previously extracted teeth were used because of periodontal problems. All teeth were examined under stereomicroscope to determine if there was any caries lesion, external resorption, crack or fracture lines. Teeth with caries lesions and calcified canal, root resorption, fractures or cracks were excluded from the study. To ensure standardization of the teeth included in the study, similar teeth were selected and digital calipers were used for this purpose. The apical $5 \mathrm{~mm}$ of each tooth was removed using a low-speed diamond bur and standardized to be $16 \mathrm{~mm}$ long. For all samples, coronal access was prepared using diamond bur in a high-speed handpiece, and the canal patency was checked by inserting \#10 K-file (Dentsply Mallefer, Swtzerland).

The specimens were instrumented to ISO size \#50 K-File. To simulate immature teeth, the canals were instrumented with Gates Glidden (Shenzhen Denco Medical Co., Ltd.) (no 1-6) until a no.5 Gates Glidden $(1,3 \mathrm{~mm})$ could be passed $1 \mathrm{~mm}$ beyond the apex and carried out instrumented to ISO size \#140 K-File with full working length for providing to $1.4 \mathrm{~mm}$ apical diameter.

The root canals were irrigated with 5,25\% $\mathrm{NaOCl}$ (Microvem, Istanbul, Turkey) during instrumentation with an irrigation needle $2 \mathrm{~mm}$ behind the apex. Cylindrical methacrylate molds were used for electronic measurement of working length. Sufficient alginate was placed in the molds and the tooth was embedded in the alginate during 
hardening. The tooth was held in this position until the alginate completely cured. During the electronic measurement, the labial clip of the positioner which was stabilized with a transparent adhesive tape was placed in the alginate. All measurements were performed at 30-minute intervals during which time the alginate was kept sufficiently moist. Working lengths of samples were measured using the Root ZX by 110, 120, 130 and 140 K-Files. All measurements were performed by one single operator. Depending on the canal size, a K-file was attached to the file holder and slowly inserted into the root canal until the EAL's digital display read $0,5 \mathrm{~mm}$. The silicone stop on the file was placed in a straight line on the incisal edge of the tooth to be the reference point for the measurement. The file was removed and measured with an endodontic ruler. Each measurement was repeated three times and averaged.

Calcium hydroxide paste (Kalsin, Aktu, Turkey) was mixed homogeneously with a spatula and drawn into the $10 \mathrm{cc}$ injector. Each sample was filled completely with calcium hydroxide paste using a 21 gauge needle before measuring. Then all the samples canal lengths were determined by the same method three times and averaged.

Statistical analysis was performed using SPSS 22.0 (SPSS, Chicago, IL, USA) for Windows. A two-way ANOVA was made to examine the effect of different size of file and the presence or absence of calcium hydroxide in the canal on the accuracy of the EAL. The data is the mean \pm standard deviation unless otherwise stated. The differences were evaluated by using Shapiro-Wilk's normality test for each design cell of normality and the homogeneity of variance was evaluated by Levene Test. All double comparisons were performed for each simple parent domain with a $95 \%$ confidence interval reported and a $\mathrm{P}$ value set with Bonferroni adjusted for each simple parent domain.

\section{Results}

Apical diameter of the root canal file increases, values near the actual length of the root canal were found and measurements in the presence of calcium hydroxide showed deviations from the actual length of the root canal. In both the presence of calcium hydroxide and measurements without calcium hydroxide, results were obtained closer to the actual canal length as the diameter of the root canal file increases. There was a statistically significant difference in the presence and absence of calcium hydroxide in the root canal with the same diameter K-file $(\mathrm{p}<0.05)$ (Table 1). The statistical difference was found between 110,130 and $140 \mathrm{~K}$-Files in the measurements performed on the empty root canal. There was a statistically significant difference between 110 and $140 \mathrm{~K}$-Files in the measurements of calcium hydroxide filled root canals $(\mathrm{p}<0.05)$ (Table 2).

Table 1: Pairwise comparison measurement of the samples with or without calcium hydroxide by the same file.

\begin{tabular}{lllllll}
\hline \multicolumn{1}{c}{ Mean Difference } & & & Std. Error & Sig. & P \\
\hline $110 \mathrm{~mm}$ & Canal Filled with Calcium Hydroxide & Blank Canal & 0,513 & 0,123 & 0,001 & $<0,05$ \\
\hline $120 \mathrm{~mm}$ & Canal Filled with Calcium Hydroxide & Blank Canal & 0,542 & 0,127 & 0,000 & $<0,05$ \\
\hline $130 \mathrm{~mm}$ & Canal Filled with Calcium Hydroxide & Blank Canal & 0,634 & 0,113 & 0,000 & $<0,05$ \\
\hline $140 \mathrm{~mm}$ & Canal Filled with Calcium Hydroxide & Blank Canal & 0,507 & 0,108 & 0,000 & $<0,05$ \\
\hline
\end{tabular}


Table 2: Pairwise comparison of different root canal files with the same samples.

\begin{tabular}{|c|c|c|c|c|c|}
\hline & & \multicolumn{2}{|c|}{ Mean Difference } & Std. Error & Sig. \\
\hline \multirow{6}{*}{ Empty Canal } & \multirow{3}{*}{$110 \mathrm{~mm}$} & $120 \mathrm{~mm}$ & 0,191 & 0,104 & 0,503 \\
\hline & & $130 \mathrm{~mm}$ & 0,345 & 0,099 & $0,015^{*}$ \\
\hline & & $140 \mathrm{~mm}$ & 0,374 & 0,099 & $0,008^{*}$ \\
\hline & \multirow{2}{*}{$120 \mathrm{~mm}$} & $130 \mathrm{~mm}$ & 0,154 & 0,047 & $0,024 *$ \\
\hline & & $140 \mathrm{~mm}$ & 0,183 & 0,074 & 0,146 \\
\hline & $130 \mathrm{~mm}$ & $140 \mathrm{~mm}$ & 0,029 & 0,052 & 1 \\
\hline \multirow{6}{*}{$\begin{array}{l}\text { Canal Filled with } \\
\text { Calcium } \\
\text { Hydroxide }\end{array}$} & \multirow{3}{*}{$110 \mathrm{~mm}$} & $120 \mathrm{~mm}$ & 0,162 & 0,104 & 0,828 \\
\hline & & $130 \mathrm{~mm}$ & 0,224 & 0,099 & 0,213 \\
\hline & & $140 \mathrm{~mm}$ & 0,38 & 0,099 & $0,007 *$ \\
\hline & \multirow{2}{*}{$120 \mathrm{~mm}$} & $130 \mathrm{~mm}$ & 0,062 & 0,047 & 1 \\
\hline & & $140 \mathrm{~mm}$ & 0,218 & 0,074 & 0,054 \\
\hline & $130 \mathrm{~mm}$ & $140 \mathrm{~mm}$ & 0,156 & 0,052 & $0,045^{*}$ \\
\hline
\end{tabular}

*Statistically significant $(P<0.05)$ compared to different file sizes

\section{Discussion}

Determining the correct working length of immature teeth during root canal treatment is necessary to promote complete cleaning and disinfection of root canals. For this purpose, EALs are able to overcome some limitations of images obtained by radiographic methods.

With developing technology, EALs are an essential part of endodontic treatment in clinic usage. The best results were reached with the latest generation devices, such as Root ZX (Dunlap et al., 1998). Electronic measurements of working length may be influenced by different factors. When the apical constriction is destroyed as a result of apical root resorption, development of incomplete root formation it is very difficult to determine the working length by radiographic methods alone (Shabahang et al., 1996).

Since there may be variability in the measurement of immature teeth using different types of EAL, one type of EAL was used in our study to standardize the measurements.

In their study, Hulsmann and Pieper showed that EAL measurements in roots with large apical foramens were significantly shorter than the actual canal length (Hulsmann and Pieper, 1989). Even if the anatomic apical constriction is impaired, the Root ZX constantly shows that the file tip is protruding from the apical. This narrowing confirms previous evidence that it defines the narrowest diameter of the canal, regardless of anatomical or mechanical occurrence (Angwaravong and Panitvisai, 2009). Electronic measurements of working length may be influenced by different file size. According to the previous studies, more successful results were obtained in electronic measurement methods as the diameter of the file was increased (Ebrahim et al., 2006; Herrera et al., 2011). In our study, more accurate results were obtained with the larger diameter files trapped in the narrowest diameter of the root canal which supports previous studies.

Many irrigation solutions are used in endodontic treatment because of its properties such as antibacterial, lubricant and ability to dissolve vital tissue (Ebrahim et al., 2006). However, the presence of any fluids may effected EAL's measurements. Some researchers have shown that the correct measurement of EAL is independent of the concentration of $\mathrm{NaOCl}$ solution and, thanks to its high electrical conductivity and its ability to penetrate dentin tubules, the root canal walls reduce the electrical impedance and also have the potential to create better electrical contact with periapical tissues (Jenkins et al., 2001; Tinaz et al., 2002; Pilot and Pitts, 1997).

Removal of all bacteria from the root canal system is normally completed by mechanical instrumentation that sutained with various irrigating solutions and antibacterial agents. Calcium hydroxide is highly advised among these intracanal medicaments and widely accepted as an interappointment antibacterial agent, that proves a pronounced antibacterial activity against most of the bacterial species defined in root canal infections (Bystrom et al., 1985).

The difference of measurement of root canal obtained by particular researchers may, according to 
Kolanu, not be caused by the size of the foramen itself, but also by the surface of contact of the active electrode with the walls (Kolanu et al., 2014).

Due to the inorganic nature of calcium hydroxide, the same samples were filled with calcium hydroxide by the hypothesis that more contact between the file and the root dentin wall will be achieved and more accurate results can be obtained. In the samples filled with calcium hydroxide, as the diameter of the file increased, the contact between the dentin wall and the file increased, the actual size of the canal was found closer to the values (Table 2). However, there was a statistically significant difference in two different measurements with $140 \mathrm{~mm}$ files. In the same measure, the calcium hydroxide group was found to be shorter than the actual length of the root canal (Table 1). Due to the irregular nature of the canal and the non-uniform distribution of the calcium hydroxide paste, incorrect results may have been obtained due to the incomplete contact between the dentin wall and the root canal file. In a study, it has been reported that calcium hydroxide residues have a negative effect on electronic measurement methods (Uzunoglu et al., 2015).

Residuel calcium hydroxide paste that obtained after irrigation may also effect the accuracy of EAL. This measurement did not reported. This could be the limitation of the present study

The removal of calcium hydroxide from radicular dentin is essential in order to provide the unity of the root canal seal. On the other hand, none of the irrigation methods used in a previous study has been reported to remove calcium hydroxide from the canal wall, leaving 25 to $45 \%$ of the surface of the walls covered with the calcium hydroxide dressing (Lambrianidis et al., 1999). More extensive studies are needed to assess the effect of different irrigation solutions and methods used to remove calcium hydroxide from the root canal wall on the accuracy of the EAL.

\section{Conclusion}

When compared to direct canal measurement, the Root ZX apex locator with larger apical diameters files tends to convenient working length of simulated immature teeth.

In the presence of calcium hydroxide in the samples, the results were found to be shorter than the actual working length.
Peer-review: Externally peer-reviewed.

Author Contributions: Concept- LBA.; DesignLBA, AÇ; Supervision- LBA; Funding- LBA; AÇ Materials- LBA; AÇ.; Data Collection/Data Process- LBA; SO, Analyze or Comment- ALB; SO; Literature Scanning- LBA; AÇ.; Writer of Paper- LBA; AÇ, SO; Critical Review- ALB; SO.

Conflict of Interest: No conflict of interest was declared by the authors.

Financial Disclosure: The authors declared that this study has /hasn't received no financial support.

\section{References}

Angwaravong $\mathrm{O}$, Panitvisai P. Accuracy of an electronic apex locator in primary teeth with root resorption. Int Endod J. 2009; 42(2):115-21.

Athanassiadis B, Abbott PV, Walsh LJ. The use of calcium hydroxide, antibiotics and biocides as antimicrobial medicaments in endodontics. Aust Dent J. 2007; 52(1):64-82.

Baldi JV, Victorino FR, Bernardes RA, de Moraes IG, Bramante CM, Garcia RB et al. Influence of embedding media on the assessment of electronic apex locators. J Endod. 2007; 33(4):476-79.

Bystrom A, Claesson R, Sundqvist G. The antibacterial effect of camphorated paramonochlorophenol, camphorated phenol and calcium hydroxide in the treatment of infected root canals. Endod Dent Traumatol. 1985; 1(5):170-75.

Dunlap CA, Remeikis NA, BeGole EA, Rauschenberger CR. An in vivo evaluation of an electronic apex locator that uses the ratio method in vital and necrotic canals. J Endodont. 1998; 24(1):48-50.

Ebrahim AK, Yoshioka T, Kobayashi C, Suda H. The effects of file size, sodium hypochlorite and blood on the accuracy of Root ZX apex locator in enlarged root canals: an in vitro study. Aust Dent J. 2006; 51(2):153-57.

Freeman BA, Crapo JD. Free-Radicals and TissueInjury. Lab Invest. 1982; 47(5):412-26.

Gordon MP, Chandler NP. Electronic apex locators. Int Endod J. 2004; 37(7):425-37.

Herrera M, Abalos C, Lucena C, Jimenez-Planas A, Llamas R. Critical diameter of apical foramen and of file size using the Root ZX apex locator: an in vitro study. J Endod. 2011; 37(9):1306-9. 
Hulsmann M, Pieper K. Use of an electronic apex locator in the treatment of teeth with incomplete root formation. Endod Dent Traumatol. 1989; 5(5):238-41.

JI Ingle, LK Bakland, DL Peters, LS Buchanan, TP Mullaney. Endodontic Cavity Preparation. In:Ingle JI, Bakland LK (Editors). Endodontics, 4th ed. Baltimore: Williams \& Wilkins. 1994:220-24.

Jeger FB, Janner SFM, Bornstein MM, Lussi A. Endodontic Working Length Measurement with Preexisting Cone-Beam Computed Tomography Scanning: A Prospective, Controlled Clinical Study. J Endodont. 2012; 38(7):884-88.

Jenkins JA, Walker WA, 3rd, Schindler WG, Flores CM. An in vitro evaluation of the accuracy of the root $\mathrm{ZX}$ in the presence of various irrigants. $\mathrm{J}$ Endod. 2001; 27(3):209-11.

Kolanu SK, Bolla N, Varri S, Thummu J, Vemuri S, Mandava P. Evaluation of Correlation Between apical Diameter and File Size Using Propex Pixi Apex Locator. J Clin Diagn Res. 2014; 8(12):1820.

Lambrianidis T, Margelos J, Beltes P. Removal efficiency of calcium hydroxide dressing from the root canal. J Endod. 1999; 25(2):85-8.

Lost C. Quality guidelines for endodontic treatment: consensus report of the European Society of Endodontology. Int Endod J. 2006; 39(12):92130.

Nguyen HQ, Kaufman AY, Komorowski RC, Friedman S. Electronic length measurement using small and large files in enlarged canals. Int Endod J. 1996; 29(6):359-64.
Pilot TF, Pitts DL. Determination of impedance changes at varying frequencies in relation to root canal file position and irrigant. J Endod. 1997; 23(12):719-24.

Pratten DH, McDonald NJ. Comparison of radiographic and electronic working lengths. J Endod. 1996; 22(4):173-76.

Shabahang S, Goon WW, Gluskin AH. An in vivo evaluation of Root ZX electronic apex locator. J Endod. 1996; 22(11):616-18.

Sharma MC, Arora V. Determination of Working Length of Root Canal. Med J Armed Forces India. 2010; 66(3):231-34.

Sjogren U, Hagglund B, Sundqvist G, Wing K. Factors affecting the long-term results of endodontic treatment. J Endod. 1990; 16(10):498-504.

Tinaz AC, Sevimli LS, Gorgul G, Turkoz EG. The effects of sodium hypochlorite concentrations on the accuracy of an apex locating device. J Endod. 2002; 28(3):160-62.

Uzunoglu E, Eymirli A, Uyanik MO, Calt S, Nagas E. Calcium hydroxide dressing residues after different removal techniques affect the accuracy of Root-ZX apex locator. Restor Dent Endod. 2015; 40(1):44-49. 